Full Paper

\title{
Electroactive Nanostructured Membranes (ENM): Synthesis and Electrochemical Properties of Redox Mediator-Modified Gold Nanoparticles Using a Dendrimer Layer-by-Layer Approach
} \author{
Christopher M. A. Brett ${ }^{\mathrm{b}}$ \\ a Instituto de Química de São Carlos, Universidade de São Paulo, 13560-970, Brazil \\ *e-mail: frank@iqsc.usp.br \\ b Departamento de Química, Universidade de Coimbra, 3004-535 Coimbra, Portugal \\ c Instituto de Física de São Carlos, Universidade de São Paulo, 13560-970, Brazil
}

Frank N. Crespilho, ${ }^{\mathrm{a}, \mathrm{c} *}$ M. Emilia Ghica, ${ }^{\mathrm{b}}$ Valtencir Zucolotto, ${ }^{\mathrm{c}}$ Francisco C. Nart, ${ }^{\mathrm{a}}$ Osvaldo N. Oliveira Jr. ${ }^{\mathrm{c}}$

Dedicated to Prof. Francisco Nart, who died during the preparation of this paper

Received: September 29, 2006

Accepted: November 22, 2006

\begin{abstract}
The layer-by-layer (LbL) self-assembly process has become an important tool in the fabrication of nanostructured devices for electrochemical applications, especially in those cases where control at the molecular level is required. In this paper we present a system based on electroactive nanostructured membranes (ENM) with ITO-PVS/PAMAM-Au LbL electrodes, in which a redox mediator $(\mathrm{Me})$ is electrodeposited around the Au nanoparticles to form an ITO-PVS/ PAMAM-Au@Me system. The redox mediators used were $\mathrm{Co}, \mathrm{Fe}, \mathrm{Ni}$ and $\mathrm{Cu}$ hexacyanoferrates. The 3-bilayer ITO-PVS/ PAMAM-Au@Me system was characterized electrochemically by cyclic voltammetry and electrochemical impedance spectroscopy. All hexacyanoferrate modified electrodes showed electrocatalytic activity towards hydrogen peroxide, thus demonstrating that this new approach can be used in biosensors and nanodevices, where a redox mediator is required.
\end{abstract}

Keywords: Layer by layer, Gold nanoparticles, Nanostructured membranes, ENM, Redox mediator, Metal hexacyanoferrates, Dendrimers

DOI: 10.1002/elan.200603775

\section{Introduction}

Studies of novel materials at the nanometer scale have been crucial in modern materials science, with nanoparticles, nanopowders and nanotubes assuming a significant role in industry, environmental applications, medicine and surface science. For electrochemistry, the use of nanoparticles and nanostructured surfaces has allowed unprecedented developments, such as in the unusual charge transport mechanisms involved in charge transfer between nanostructured materials and electrode surfaces [1,2]. Significantly, some interfacial phenomena only appear when nanostructured materials are immobilized on electrode surfaces, which can be of organic and/or inorganic materials. Furthermore, nanomaterials have been applied in bioelectrochemistry, including cases where environmentally-friendly systems with DNA [3], enzymes [2, 3] and other biomolecules [2] are used.

In spite of the remarkable progress in recent years, there are still a number of points to be addressed, such as the establishment of appropriate processes and molecules for immobilization of nanomaterials at electrodes. The combination of dendrimers [1] and the layer-by-layer (LbL) technique [4] has been proven excellent for electroactive nanostructured materials [2]. Dendrimers have been widely used in pharma- cological applications, synthesis of nanoparticles and biosensors $[1,2,5]$, with polyamidoamine (PAMAM) molecules being the most used ones $[1,5]$. For the synthesis of nanoparticles, in particular, Crooks et al. suggested a strategy [6-9] in which metallic nanoparticles are prepared in a homogenous phase, with metallic cations being reduced-stabilized to metallic nanoparticles in an aqueous solution containing PAMAM and a reduction agent. PAMAM dendrimers possess cavities that serve as template for stabilization of the nanoparticles (Scheme 1a), while the functional groups allow fabrication of layer-by-layer (LbL) $[1,2]$ films with PAMAM-nanoparticle architectures as shown in Scheme $1 \mathrm{~b}$.

We have recently explored the capability of $\mathrm{Au}$ nanoparticles to enhance the charge transport in nanostructured films [1] and produce electroactive nanostructured membranes (ENM). PAMAM-containing metallic nanoparticles have been assembled in LbL films onto conducting substrates and used as modified electrodes [1, 5, 10], such as in methanol-tolerant cathodes for direct-methanol fuel cells [5]. Our previous investigations $[1,10]$ have involved indium tin oxide (ITO) substrates on glass, with polyvinylsulfonate (PVS) as negatively charged polyelectrolyte alternating with the positively charged PAMAM in the LbL film structure. 
a)

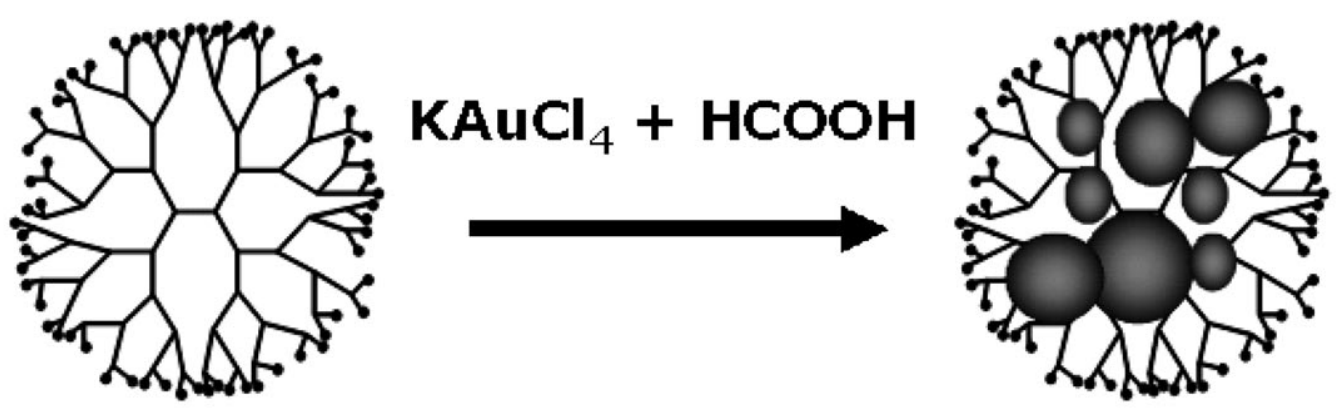

b)

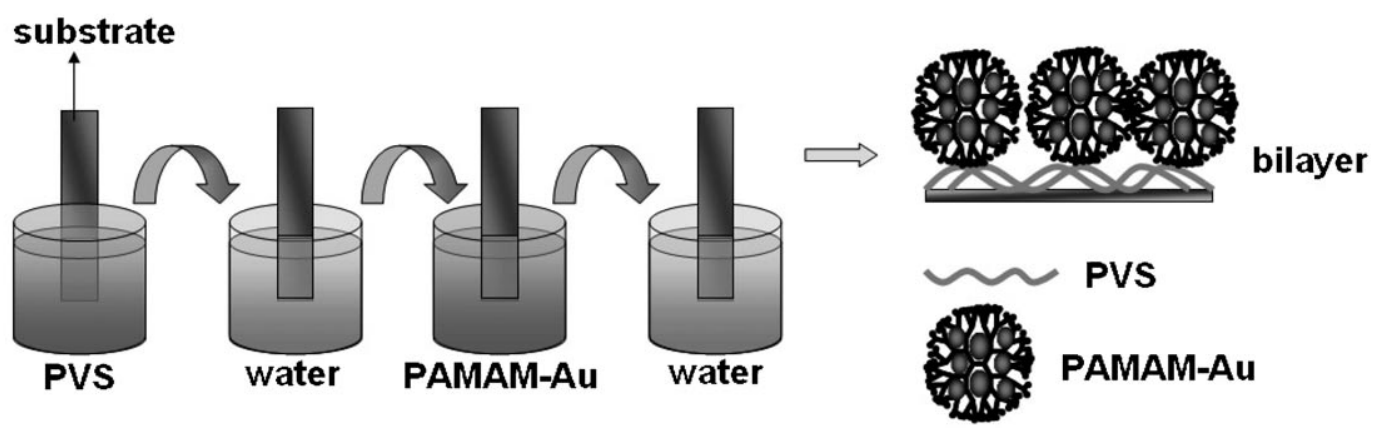

Scheme 1. Schematic fabrication of LbL films comprising PVS and PAMAM-Au. a) Formation of PAMAM-Au. b) Sequential deposition of LbL multilayers by immersing the substrates alternately into PVS and PAMAM-Au solutions for 5 min. Before each deposition step, the excess of nonadsorbed molecules was removed by immersing the substrate in water.

In this work we show a system based on electroactive nanostructured membranes (ENM) of ITO-PVS/PAMAM$\mathrm{Au} \mathrm{LbL}$ electrodes, in which a redox mediator $(\mathrm{Me})$ is electrodeposited around the $\mathrm{Au}$ nanoparticles to form an ITO-PVS/PAMAM-Au@Me system. The formation of electroactive nanostructured membranes (ENM) made up with an ITO-PVS/PAMAM-Au@Me system was demonstrated in [2], which could be exploited for enzyme immobilization leading to very efficient biosensors [10]. Here we show that the concept can be generalized to other mediators, namely $\mathrm{Co}, \mathrm{Fe}, \mathrm{Ni}$ and $\mathrm{Cu}$ hexacyanoferrates. The latter compounds were chosen because metal hexacyanoferrate films may transfer electrons during reduction and oxidation processes. We also investigate the reduction reaction of hydrogen peroxide in ITO-PVS/PAMAM$\mathrm{Au} @ \mathrm{Me}$ heterostructures, mainly to verify the electrocatalytic properties of the PAMAM-Au@Me system. The heterostructures are studied with field-emission scanning electron microscopy (FE-SEM) and electrochemical impedance spectroscopy (EIS).

\section{Experimental}

\subsection{Materials and Methods}

All chemicals were reagent grade, used as received. All solutions were prepared using ultrapure, Millipore (Milli-
Q) water (resistivity $\geq 18 \mathrm{M} \Omega \mathrm{cm})$. Cobalt chloride $\left(\mathrm{CoCl}_{2}\right)$, copper chloride $\left(\mathrm{CuCl}_{2}\right)$, nickel chloride $\left(\mathrm{NiCl}_{2}\right)$, and potassium hexacyanoferrate $\left(\mathrm{K}_{3} \mathrm{Fe}(\mathrm{CN})_{6}\right)$ were from Merck, Germany; iron chloride $\left(\mathrm{FeCl}_{3}\right)$ was from Riedel de Haën. Germany. Hydrogen peroxide $\left(\mathrm{H}_{2} \mathrm{O}_{2}\right) 35 \%$ was acquired from José M. Vaz Pereira. Lisbon. G4 PAMAM dendrimers were purchased from Aldrich, Germany. Electrochemical measurements were performed in a $15 \mathrm{~mL}$, onecompartment cell, containing the ITO modified electrode (working electrode), a platinum auxiliary electrode and saturated calomel electrode (SCE) as reference electrode.

Voltammetric experiments were carried out using a CV$50 \mathrm{~W}$ Voltammetric Analyzer from Bioanalytical Systems, West Lafayette, IN, controlled by BAS CV-2.1 software. Electrochemical impedance measurements were carried out using a Solartron 1250 Frequency Response Analyzer, coupled to a Solartron 1286 Electrochemical Interface controlled by Zplot software. The frequency range used was $65 \mathrm{kHz}$ to $0.1 \mathrm{~Hz}$ with 10 frequencies per decade. The $\mathrm{pH}$ measurements were carried out with a CRISON 2001 micro $\mathrm{pH}$-meter at room temperature. The morphology and particle size distribution were characterized using a 200$\mathrm{kV}$ transmission electron microscope (TEM, Model CM200; Philips, Eindhoven, the Netherlands) and scanning electron micrographs (SEM) were obtained by field emission scanning electron microscopy (FE-SEM; Zeiss, Supra 35 at $2 \mathrm{kV}$ ). UV-vis spectroscopy was performed using a Hitachi U-2001 Spectrophotometer; San Jose, CA, USA. 


\subsection{PAMAM-Au Synthesis}

Nanohybrids were prepared as follows: $2 \mathrm{~mL}$ of $\mathrm{KAuCl}_{4}$ solution $\left(1 \mathrm{mmol} \mathrm{L}^{-1}\right)$ were added to $2 \mathrm{~mL}$ of PAMAM $\left(0.07 \mathrm{mmol} \mathrm{L}^{-1}\right)$ and $2 \mathrm{~mL}$ of formic acid $\left(1 \mathrm{mmol} \mathrm{L}^{-1}\right)$. This pale yellow solution was vigorously stirred for $2 \mathrm{~min}$. When the zerovalent Au complex was formed the color immediately changed from yellow to red. This reaction occurred during $4 \mathrm{~h}$ and the nanoparticle growth kinetics was followed by UV-vis spectrophotometry. The morphology and particle size distribution were characterized by TEM; the particle size distribution was estimated by measuring at least 200 particles in TEM images.

\subsection{PVS/PAMAM-Au Multilayer Self-Assembly}

LbL films were assembled onto ITO-coated glass. The concentration of the dipping solutions was set at $0.07 \mathrm{mmol}$ $\mathrm{L}^{-1}$ and $0.5 \mathrm{~g} \mathrm{~L}^{-1}$ for PAMAM-Au and PVS, respectively. The sequential deposition of multilayers was carried out in a HMS series programmable slide stainer (Carl Zeiss Inc, Jena, Germany) by immersing the substrates alternately into the PAMAM-Au and PVS solutions for $5 \mathrm{~min}$. After deposition of each layer, the substrate/film system was rinsed with water and dried in $\mathrm{N}_{2}$.

\subsection{Redox Mediator Electrodeposition}

The electrochemical formation of the metal hexacyanoferrate films was performed by continuous cycling of the potential of the working electrode in a defined potential range in an appropriate aqueous solution. Electrochemical depositions were performed as follows. For cobalt hexacyanoferrate, the electrode was cycled 30 times between -0.2 and $0.9 \mathrm{~V}$ vs. SCE at a scan rate of $50 \mathrm{mV} \mathrm{s}^{-1}$ in a freshly prepared solution containing $0.5 \mathrm{mmol} \mathrm{L}^{-1} \quad \mathrm{CoCl}_{2}$, $0.25 \mathrm{mmol} \mathrm{L}^{-1} \mathrm{~K}_{3} \mathrm{Fe}(\mathrm{CN})_{6}$ and $0.05 \mathrm{~mol} \mathrm{~L}^{-1} \mathrm{NaCl}$ at $\mathrm{pH} 3$ ( $\mathrm{pH}$ adjusted with $\mathrm{HCl}$ ). For copper hexacyanoferrate, the electrode was cycled 30 times between -0.35 and $0.9 \mathrm{~V}$ vs. SCE at a scan rate of $100 \mathrm{mV} \mathrm{s}^{-1}$ in a freshly prepared solution containing $1 \mathrm{mmol} \mathrm{L}^{-1} \mathrm{CuCl}_{2}, 1 \mathrm{mmol} \mathrm{\textrm {L } ^ { - 1 }} \mathrm{K}_{3}$ $\mathrm{Fe}(\mathrm{CN})_{6}$ and $0.1 \mathrm{~mol} \mathrm{~L}^{-1} \mathrm{KCl}$ at $\mathrm{pH} 3$ (pH adjusted with $\mathrm{HCl})$. For iron hexacyanoferrate, cycling was done 30 times between -0.35 and $1.1 \mathrm{~V}$ vs. SCE at a scan rate of $10 \mathrm{mV} \mathrm{s}^{-1}$ in a freshly prepared solution containing $1 \mathrm{mmol} \mathrm{L}^{-1} \mathrm{FeCl}_{3}$, $1 \mathrm{mmol} \mathrm{L}^{-1} \mathrm{~K}_{3} \mathrm{Fe}(\mathrm{CN})_{6}$ in $0.1 \mathrm{~mol} \mathrm{~L}^{-1} \mathrm{KCl}+0.1 \mathrm{M} \mathrm{HCl}$ ( $\mathrm{pH} \sim 1)$. Finally, for nickel hexacyanoferrates, the electrode was cycled 30 times between -0.2 and $0.9 \mathrm{~V}$ vs. SCE at a scan rate of $100 \mathrm{mV} \mathrm{s}^{-1}$ in a freshly prepared solution containing $2.5 \mathrm{mmol} \mathrm{L}^{-1} \mathrm{NiCl}_{2}, 2.5 \mathrm{mmol} \mathrm{L}^{-1} \mathrm{~K}_{3} \mathrm{Fe}(\mathrm{CN})_{6}$ and $0.6 \mathrm{~mol} \mathrm{~L}^{-1} \mathrm{KCl}$ at $\mathrm{pH} 2$ (pH adjusted with $\mathrm{HCl}$ ).

\subsection{Catalytic Properties of ITO-(PVS/PAMAM-Au) Electrodes}

In order to verify the electrocatalytic properties of the PAMAM-Au@Me system, cyclic voltammograms were recorded in a $\mathrm{pH} 6.750 .1 \mathrm{M}$ potassium phosphate buffer
(KPB) at a scan rate of $50 \mathrm{mV} \mathrm{s}^{-1}$ and with addition of $1 \mathrm{mmol} \mathrm{L}^{-1}$ and $5 \mathrm{mmol} \mathrm{L}^{-1}$ hydrogen peroxide.

\section{Results and Discussion}

\subsection{PAMAM-Au Synthesis}

PAMAM-Au nanoparticles were synthesized in aqueous solution using formic acid, G4 PAMAM and $\mathrm{KAuCl}_{4}$. The reduction of $\mathrm{Au}^{3+}$ to $\mathrm{Au}^{0}$ and the formation of $\mathrm{Au}$ nanoparticles stabilized by PAMAM molecules were monitored by UV-vis spectroscopy, as shown in Figure 1a. An initial reduction stage is seen by the decrease in the $300 \mathrm{~nm} \mathrm{AuCl}_{4}{ }^{-}$ band. A peak around $500 \mathrm{~nm}$ associated with the plasmon resonance appears and an increase in the baseline due to scattering effects is also observed. In addition, the band at $300 \mathrm{~nm}$ assigned to the electronic absorption from $\mathrm{AuCl}_{4}{ }^{-}$ vanishes after $100 \mathrm{~min}$ of reaction, indicating the formation of metallic $\mathrm{Au}$. Note that Figure 1a resembles similar ones presented in [2], but now including the kinetics of PAMAMAu formation through monitoring the surface plasmon band at $550 \mathrm{~nm}$. Monitoring the peak at $500 \mathrm{~nm}$, the reaction kinetics was obtained (Fig. 1a, inset) and nanoparticle growth was complete after $200 \mathrm{~min}$. The stabilization of $\mathrm{Au}$ nanoparticles in aqueous solution occurs probably because the nanoparticles can be encapsulated within PAMAM cavities. Evidence for such encapsulation appeared in previous work [1], in which the FTIR spectra in the transmission mode were compared for neat PAMAM and PAMAM-Au. The band at $1449 \mathrm{~cm}^{-1}$ assigned to the amide band II from inside the PAMAM molecule split into two bands, indicating that the amide group could be attached to the gold nanoparticles.

After 200 min of reaction, the Au nanoparticles formed showed a well-organized distribution, with a particle diameter of ca. $3 \mathrm{~nm}$ as shown in Figure 1b. The solution of PAMAM-Au nanoparticles was used as a cationic component to prepare LbL films, owing to the PAMAMAu's positive charge deriving from the presence of protonated amine groups in the PAMAM-Au nanocomposite [1, 10]. Also, X-ray diffractograms of PAMAM-Au cast films (not shown) enabled identification of the (111), (200) and (220) atomic planes of the Au nanoparticles [11].

\subsection{Fabrication of LbL Films of PVS/PAMAM-Au}

ITO electrodes were modified with PVS/PAMAM-Au multilayers in a layer-by-layer fashion. The sequential deposition was performed by immersing the ITO substrate alternately into the PAMAM-Au and PVS solutions for 5 min (Scheme 1b). This deposition time was used based on previous work $[1,5,10]$, where it was also found that optimized electrodes had 3 bilayers of PVS/PAMAM-Au [10].

Figure 2 shows cyclic voltammograms for ITO-(PAMAM-Au $)_{n}$ in $\mathrm{H}_{2} \mathrm{SO}_{4} 0.1 \mathrm{~mol} \mathrm{~L}{ }^{-1}$, with $n=1,2$ and 3 
a)

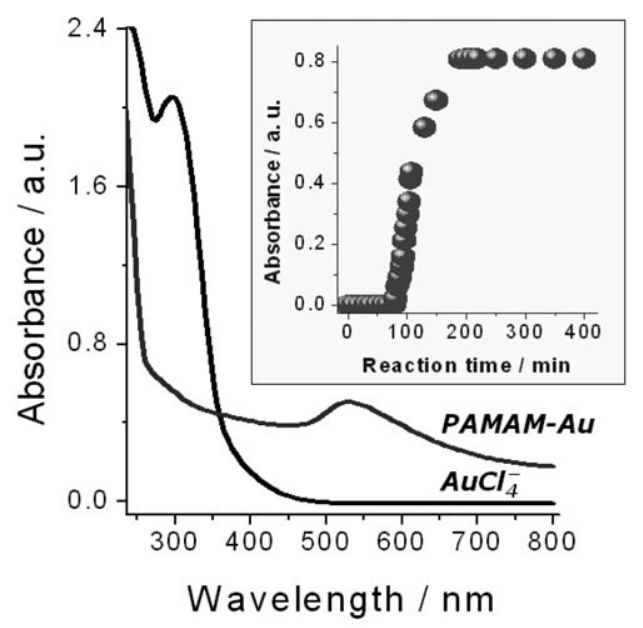

b)

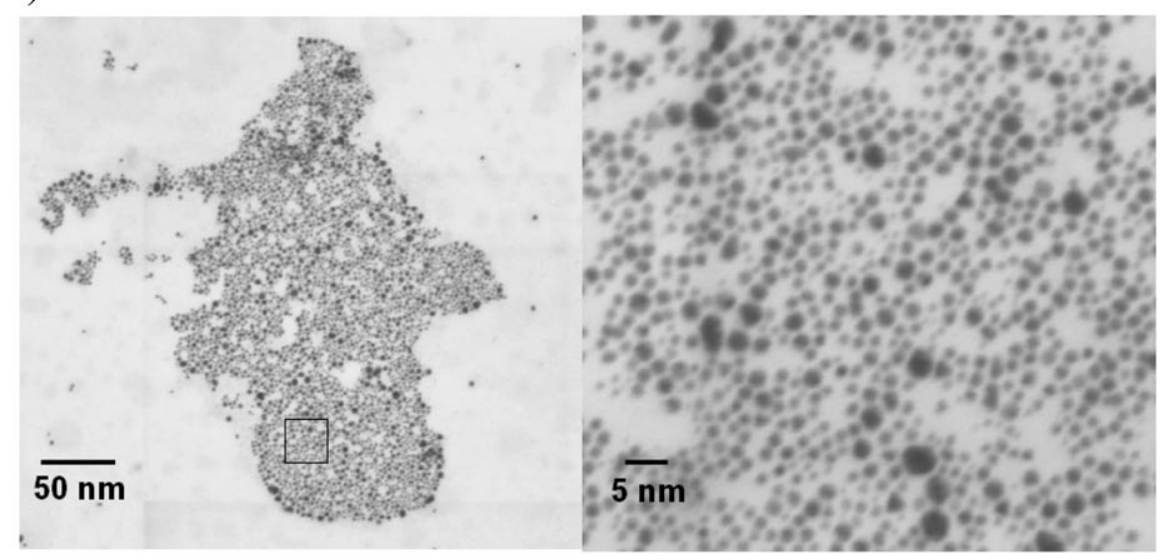

Fig. 1. a) UV-vis spectroscopy before and after gold nanoparticle formation inside PAMAM molecules. The inset shows the absorbance at $550 \mathrm{~nm}$ for various reaction times. b) Bright-field STEM image of Au nanoparticles.

bilayers. An oxidation peak is observed at $+1.2 \mathrm{~V}$ (vs. Ag/ $\mathrm{AgCl}$ ), while the reduction peak at $+1.0 \mathrm{~V}$ (inset of Fig. 2) was attributed to the reduction of $\mathrm{Au}$ oxides at the nanoparticle surface. Cyclic voltammetry was used to probe the evolution of the multilayer deposition step by step, in order to verify the film electroactivity and the amount of Aunanoparticles deposited in each step. In the PVS/PAMAM$\mathrm{Au}$ system, the same amount of material was adsorbed in each layer, shown by the linear increase of the reduction peak current. Important inferences can be made from this result: first, charge transport occurs from the electrode substrate to the external solution or vice-versa, with charge transport within redox sites of Au nanoparticles occurring via electron hopping. Second, since Au-nanoparticles are immobilized inside the PAMAM molecules, the electrons must flow between the nanoparticles and the electrode, with the ions released by the water to form oxide diffusing so as to keep the film electrically neutral. This is consistent with the finding that electrochemically-active polyelectrolytes can be incorporated in multilayer structures [12].

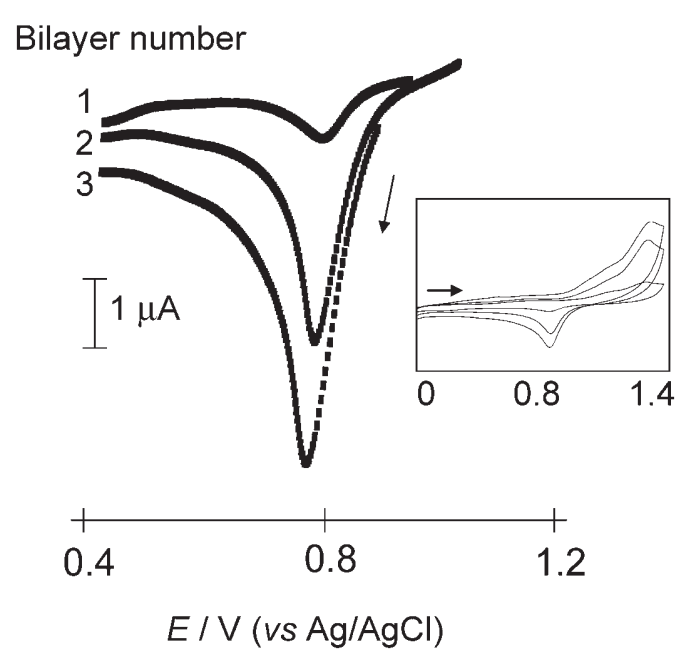

Fig. 2. Linear scan (cathodic) of ITO-(PVS/PAMAM-Au) $)_{n}$ with different numbers of bilayers $(n=1,2$, and 3$)$. In the inset, cyclic voltammograms of ITO-(PVS/PAMAM-Au) $)_{n}$; scan rate $50 \mathrm{mV} \mathrm{s}^{-1}$. Electrolyte solution: $0.5 \mathrm{~mol} \mathrm{~L}^{-1} \mathrm{H}_{2} \mathrm{SO}_{4}$. 
a)

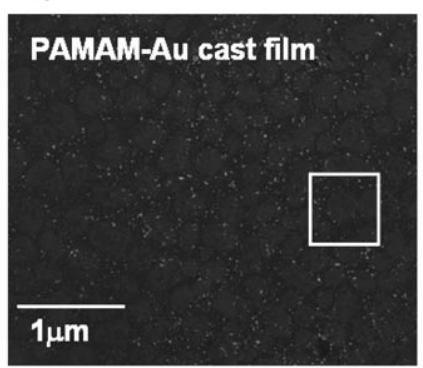

c)

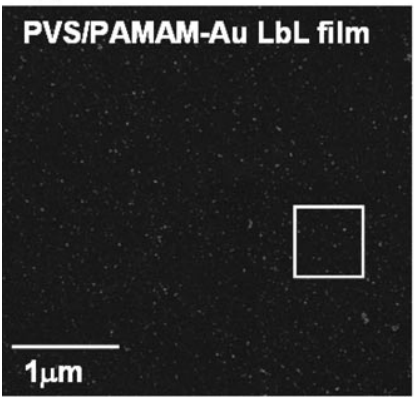

b)

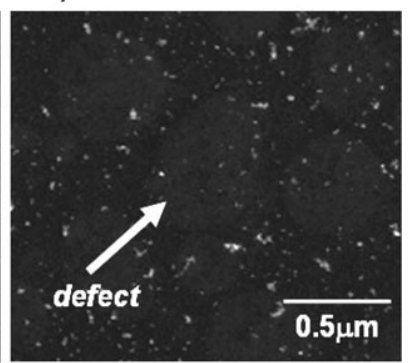

d)

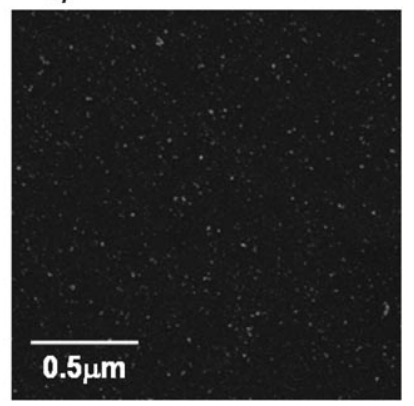

Fig. 3. Scanning electron micrographs (SEM) obtained by field emission scanning electron microscopy (FE-SEM at $2 \mathrm{kV}$ ) for a), b) PAMAM-Au cast film and c), d) 1-bilayer PVS/PAMAM-Au LbL film.

Electron hopping is believed to occur due to the good organization of the LbL films, as has been widely recognized in the literature. This can be confirmed by comparing the LbL with a cast film. Figure 3 show SEM micrographs of a cast film of PAMAM-Au and a 1-bilayer PVS/PAMAM-Au, both deposited onto Si substrates. When the PAMAM-Au is deposited as a simple drop of solution (cast film) on $\mathrm{Si}$, defects are identified with cavities from 3 to $6 \mu \mathrm{m}$, around which PAMAM-Au agglomerates. On the other hand, the PVS/PAMAM-Au film using the LbL approach is more homogeneous, with a uniform distribution of nanoparticles.

\subsection{Immobilization of the Redox Mediator: Core-Shell PAMAM-Au@Me System}

A modified electrode, ITO-(PVS/PAMAM-Au) $)_{3}$, was used as working electrode for preparation and characterization of hexacyanoferrate films on Au nanoparticles. The concept of mediators electrodeposited around $\mathrm{Au}$ nanoparticles was introduced in $[1,10]$. Interest in metal hexacyanoferrates arises from the possible reversible electron transfer and associated color changes. The ability to immobilize them on the electrode surfaces is a key factor for various applications such as electrochromism [13], electrocatalysis [14], corrosion protection [15], sensors and biosensors [16-18]. Electrochemical deposition of hexacyanoferrates has been proven to be suitable for achieving reproducible films with reversible behavior [16-22], but the process needs to be carefully controlled. The fabrication of an electrochemically-modified film electrode is easily controlled by using

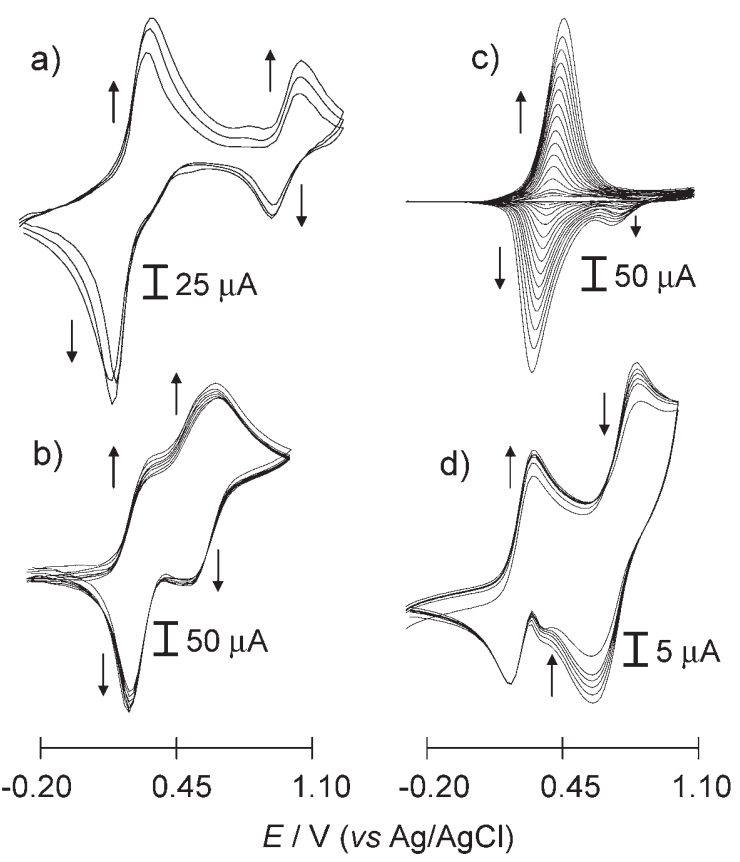

Fig. 4. Cyclic voltammograms showing continuous growth of a) FeHCF, b) NiHCF, c) CoHCF, and d) CuHCF on ITO-(PVS/ PAMAM-Au $)_{3}$ electrodes.

consecutive cyclic voltammetry as a synthetic procedure, in which an increase in the peak current of the mediator-layers forms an appropriate redox couple for the modified film [19]. The most common strategy for electrosynthesis of metal hexacyanoferrates involves potentiodynamic cycling between preset potential limits of the working electrode in a supporting electrolyte containing both the metal ion $\left(\mathrm{M}^{n+}\right)$ and ferricyanide species [23]. In this work we employed this experimental procedure to prepare all hexacyanoferrate compounds.

Deposition of iron hexacyanoferrates (FeHCF) was carried out using the method described in [24]. Figure 4a illustrates three consecutive cyclic voltammograms showing Prussian Blue (PB) modification of the electrode. The electrochemical behavior is dominated by two sets of voltammetric peaks that originate from PB reactions: the oxidation of Prussian Blue to iron(III) hexacyanoferrate(III), Prussian Yellow, at around $+0.9 \mathrm{~V}$, and the reduction of Prussian Blue to iron(II) hexacyanoferrate(II), Prussian White, at ca. 0.2 V. The deposition was very fast; and all the peaks increased in height up to 10 cycles. The result was a stable PB modified electrode. Significantly, peak currents are proportional to scan rate up to $300 \mathrm{mV} \mathrm{s}^{-1}$ (Fig. 5a), which is consistent with a fast charge propagation in the film.

Nickel hexacyanoferrate (NiHCF) was formed on the electrode surface using the method described by Milardović et al. [25]. Figure 4b summarizes voltammetric results obtained by monitoring the growth of NiHCF on the ITO/ PVS/PAMAM-Au electrode. During the whole experiment, two well-defined sets of peaks appeared, which slowly 

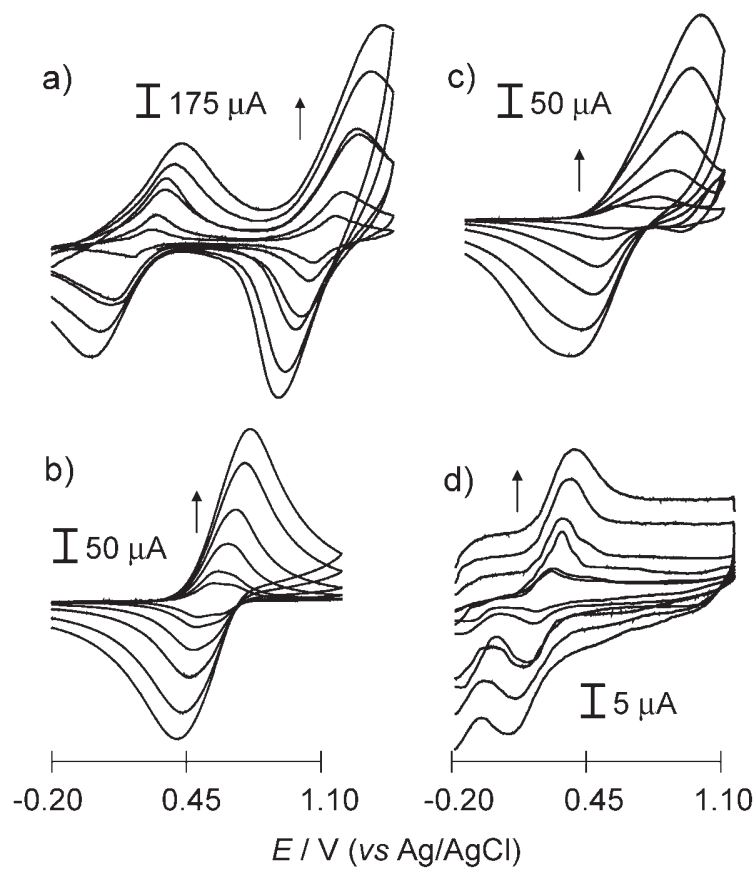

Fig. 5. Cyclic voltammograms of a) FeHCF, b) NiHCF, c) $\mathrm{CoHCF}$, and d) $\mathrm{CuHCF}$ modified electrodes in $0.1 \mathrm{M} \mathrm{KPB}$ $(\mathrm{pH}$ 6.75) at different scan rates.

increased up to 30 cycles. It is assumed that, during the potential cycling, NiHCF is formed with simultaneous insertion of $\mathrm{K}^{+}$. These two sets of voltammetric peaks were explained by the existence of two predominating forms of NiHCF [26]. The more positive set of peaks is usually attributed to $\mathrm{K}_{2} \mathrm{Ni}\left[\mathrm{Fe}^{\mathrm{II}}(\mathrm{CN})_{6}\right] / \mathrm{KNi}\left[\mathrm{Fe}^{\mathrm{III}}(\mathrm{CN})_{6}\right]$ that are $\mathrm{K}^{+}$rich and more strongly paired by potassium ions. The NiHCF modified electrode was then transferred to $0.1 \mathrm{M}$ KPB buffer solution and the influence of the scan rate on the cyclic voltammograms was studied. As seen in Figure 5b, only at very low scan rates (e.g., $10 \mathrm{mV} \mathrm{s}^{-1}$ ) was it possible to distinguish the two sets of redox pairs. At high scan rates, only one pair of well-defined peaks appeared, which was attributed to hexacyanoferrate(III/II) [27]. Both anodic and cathodic peak currents increased linearly with scan rate up to $300 \mathrm{mV} \mathrm{s}^{-1}$ as expected in a system with no diffusion dependence.

For cobalt hexacyanoferrate (CoHCF), the method reported in [20] was used, where continuous film growth is indicated by the voltammograms in Figure 4c. The current increases for consecutive voltammograms, indicating CoHCF layer formation and an increase of the charge under the deposition peak. The film formed was characterized in $0.1 \mathrm{M} \mathrm{KPB}(\mathrm{pH} 6.75$ ) and typical cyclic voltammograms obtained at different scan rates are presented in Figure 5c. A pair of redox peaks is observed, which might correspond to both processes $\mathrm{Co}^{\mathrm{II}} \rightleftharpoons \mathrm{Co}^{\mathrm{III}}$ and $\left[\mathrm{Fe}^{\mathrm{III}}\right.$ $\left.(\mathrm{CN})_{6}\right]^{3-} /\left[\mathrm{Fe}^{\mathrm{II}}(\mathrm{CN})_{6}\right]^{4-}$ occurring simultaneously. Peak currents increased linearly with scan rate up to $300 \mathrm{mV} \mathrm{s}^{-1}$, as for nickel hexacyanoferrate. The anodic and cathodic peak potentials shifted symmetrically, the peak separation increasing with increasing scan rate.

Copper hexacyanoferrate (CuHCF) films were prepared by cyclic voltammetry as in [21] but using lower precursor concentrations. During deposition, the cyclic voltammograms exhibited two pairs of redox peaks (Fig. 4d), which were attributed by Shankaran [22] to the $\mathrm{Cu}^{\mathrm{I}} \rightleftharpoons \mathrm{Cu}^{\mathrm{II}}$ and $\left[\mathrm{Fe}^{\mathrm{II}}(\mathrm{CN})_{6}\right]^{4-} \rightleftharpoons\left[\mathrm{Fe}^{\mathrm{III}}(\mathrm{CN})_{6}\right]^{3-}$ couples. The magnitude of the currents in the first pair of peaks points to rapid deposition up to ten cycles, after which deposition was slower up to 20 cycles, and then ceased. The currents corresponding to the second pair of peaks decreased slightly up to 10 cycles, and this decrease became more pronounced after the $20^{\text {th }}$ cycle. This was probably due to the formation of a thick film of $\mathrm{CuHCF}$, thus hindering electron transfer. The film formed showed a peculiar behavior with the second pair of peaks showing a scan rate dependence up to $50 \mathrm{mV} \mathrm{s}^{-1}$, above which it disappeared. This might be indicative of film instability. However, a pronounced dependence on scan rate for the first pair of peaks up to $300 \mathrm{mV} \mathrm{s}^{-1}$ is seen in Figure 5d. A small peak potential shift was observed with increasing scan rate, but was less pronounced than for $\mathrm{CoHCF}$.

\subsection{Electrochemical Impedance of ITO-PVS/PAMAM- Au@Me Electrodes}

The electrochemical properties of hexacyanoferrate films have been studied by electrochemical impedance spectroscopy (EIS) [28], and the data analyzed with various models and equivalent circuits [24-29]. The strategy used here to study diffusional and charge-transport mechanisms was to analyze the impedance at high frequencies for ITO-(PVS/ PAMAM-Au $)_{3}$ electrodes, before and after immobilization of a redox mediator. In the former case, the spectra were taken immediately after immersing the ITO-(PVS/PA$\mathrm{MAM}-\mathrm{Au})_{3}$ electrode in the redox mediator precursor solution. After cycling to immobilize the redox mediator, the spectra of the new system containing Au@Me were recorded. The results obtained at the open circuit potential are shown in Figure 6, with a semicircle at high frequencies in the complex plane plots after redox mediator immobilization. By comparing EIS spectra of different electrodeposited mediators, some important features were noted: The spectra collected after Me deposition differed from ITO-(PVS/PAMAM-Au $)_{3}$ electrodes with no mediator. The charge transfer between Au@Me and ITO electrodes is faster and the charge transfer resistance decreases in the sequence $\mathrm{CuHCF}>\mathrm{FeHCF}>\mathrm{NiHCF}>\mathrm{CoHCF}$.

\subsection{Catalytic Properties of ITO-PVS/PAMAM-Au@Me Electrodes}

Catalytic properties of the hexacyanoferrates formed at ITO/PVS/PAMAM-Au electrodes are demonstrated in Figure7. Cyclic voltammograms were recorded in $0.1 \mathrm{M}$ 
a)

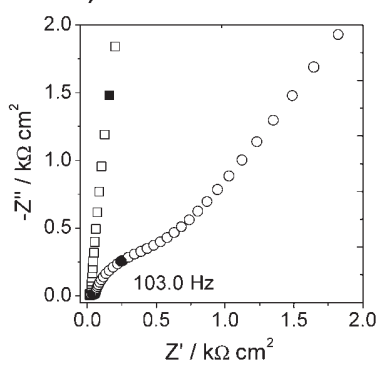

b)

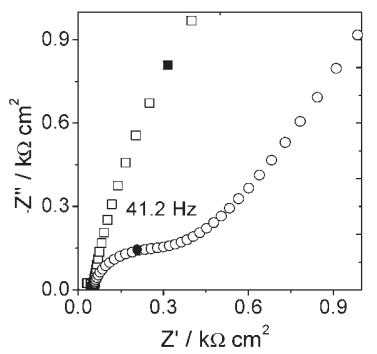

c)

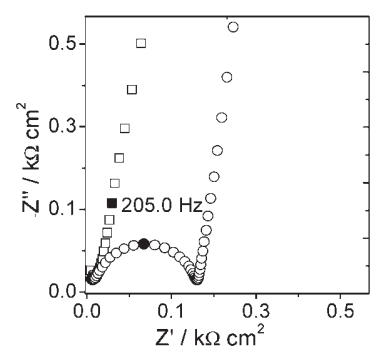

d)

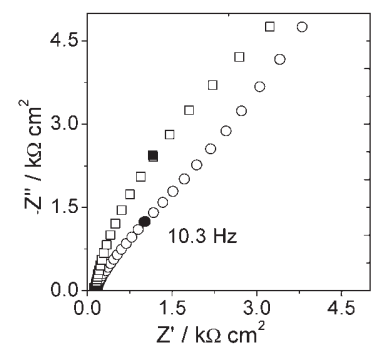

Fig. 6. Complex plane impedance spectra for 3-bilayer PVS/ PAMAM before $(-\square-)$ and after $(-\bullet-)$ redox mediator electrodeposition. a) FeHCF, b) NiHCF, c) $\mathrm{CoHCF}$, and d) $\mathrm{CuHCF}$ at open circuit potential, frequency range from $65 \mathrm{kHz}$ to $0.1 \mathrm{~Hz}$.
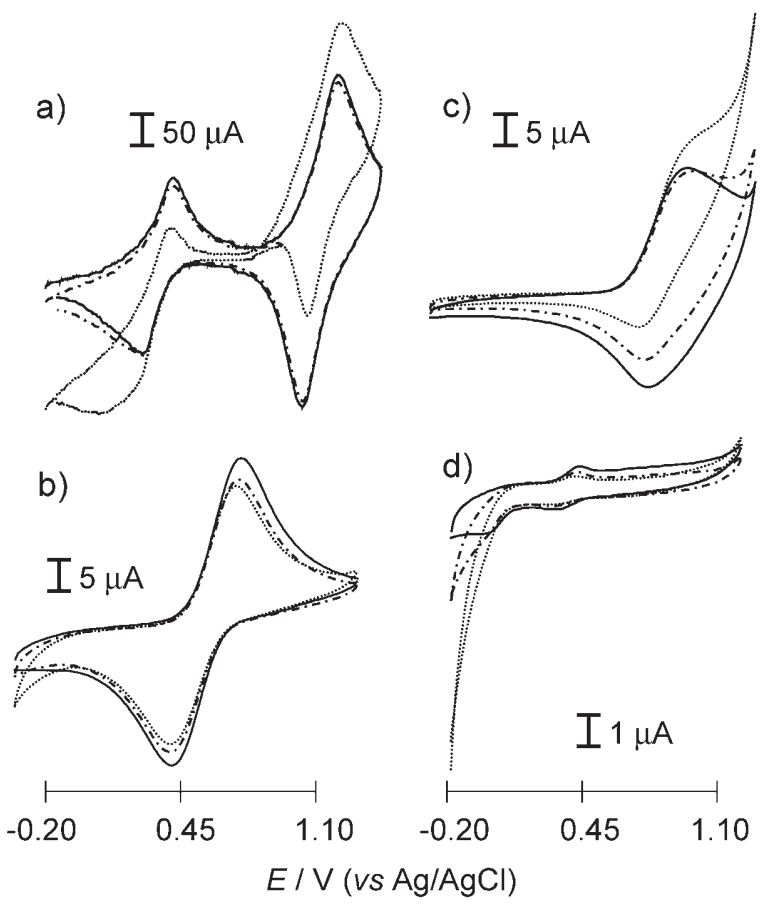

Fig. 7. Cyclic voltammograms of a) FeHCF, b) NiHCF, c) $\mathrm{CoHCF}$, and d) $\mathrm{CuHCF}$ modified electrodes in $0.1 \mathrm{M} \mathrm{KPB}$ (pH 6.75) (solid line) and after addition of $1 \mathrm{mmol} \mathrm{L}^{-1} \mathrm{H}_{2} \mathrm{O}_{2}$ (dotted line) and $5 \mathrm{mmol} \mathrm{L}{ }^{-1} \mathrm{H}_{2} \mathrm{O}_{2}$ (dashed line).

$\mathrm{KPB}\left(\mathrm{pH}\right.$ 6.75) at a scan rate of $50 \mathrm{mV} \mathrm{s}^{-1}$ and with addition of $1 \mathrm{mmol} \mathrm{L}^{-1}$ and $5 \mathrm{mmol} \mathrm{L}{ }^{-1}$ hydrogen peroxide to study the electrocatalytic effect at low and high peroxide concen-

trations. All hexacyanoferrate-modified electrodes showed electrocatalytic activity towards hydrogen peroxide, but there were differences depending on the mediator. For NiHCF (Fig. 7b) and CuHCF (Fig. 7d), the effect of peroxide on the cyclic voltammograms was the same: upon addition of $1 \mathrm{mmol} \mathrm{L}^{-1} \mathrm{H}_{2} \mathrm{O}_{2}$ a decrease in both oxidation and reduction peaks was observed, probably due to interaction of the analyte with the mediator. Peroxide reduction occurred at ca. $-0.2 \mathrm{~V}$ in both cases, which is more clearly visualized for NiHCF following addition of a higher concentration of peroxide. In the case of FeHCF (Fig. 7a), the peak current did not alter upon addition of peroxide, and the increase in the cathodic current around $+0.1 \mathrm{~V}$ can be attributed to reduction of hydrogen peroxide. As for CoHCF (Fig. 7c), a catalytic effect occurred only at high peroxide concentrations and an increase in the oxidation peak was visible at $+0.7 \mathrm{~V}$. With small amounts of peroxide, only a decrease in the reduction peak was observed, probably due to the reaction of peroxide with the mediator.

\section{Conclusions}

New systems are described based on ENM membranes of ITO-PVS/PAMAM-Au LbL electrodes, with a redox mediator $(\mathrm{Me})$ electrodeposited around Au nanoparticles. The resulting ITO-PVS/PAMAM-Au@Me system was characterized electrochemically using cyclic voltammetry and electrochemical impedance spectroscopy. We demonstrated that the concept of ENM can be generalized to a wider variety of redox mediators. All electrodes modified with hexacyanoferrates showed electrocatalytic activity towards hydrogen peroxide, which is promising for the preparation of novel biosensors and nanodevices requiring redox mediators.

\section{Acknowledgements}

Financial support from FAPESP, CAPES (process number 1238/05-1), CNPq, IMMP/MCT (Brazil), European Project HPRN-CT-2002-00186, Fundação para a Ciência e Tecnologia (FCT) Portugal (SFRH/BD/14014/2003-MEG) and ICEMS (Research Unit 103), is gratefully acknowledged. The authors are also indebted to Prof. Dr. E. R. Leite for his help in the TEM and FE-SEM data.

\section{References}

[1] F. N. Crespilho, V. Zucolotto, C. M. A. Brett, O. N. Oliveira Jr., F. C. Nart, J. Phys. Chem. B 2006, 110, 17478.

[2] F. N. Crespilho, V. Zucolotto, J. R. Siqueira Jr., A. J. F. Carvalho, F. C. Nart, O. N. Oliveira Jr., Int. J. Electrochem. Sci. 2006, 1, 151.

[3] X. Luo, A. Morrin, A. J. Killard, M. R. Smyth, Electroanalysis 2005, 18, 319.

[4] G. Decher, Science 1997, 277, 1232. 
[5] F. N. Crespilho, F. Huguenin, V. Zucolotto, P. Olivi, F. C. Nart, O. N. Oliveira Jr., Electrochem. Commun. 2006, 8, 348.

[6] M. Q. Zhao, R. M. Crooks, Adv. Mater. 1999, 11, 217.

[7] M. Q. Zhao, R. M. Crooks, Chem. Mater. 1999, 11, 3379.

[8] H. Ye, R. M. Crooks, J. Am. Chem. Soc. 2005, 127, 4930.

[9] Y-G. Kim, S-K Oh, R. M. Crooks, Chem. Mater. 2004, 16, 167.

[10] F. N. Crespilho, M. E. Ghica, M. Florescu, F. C. Nart, O. N. Oliveira Jr., C. M. A. Brett, Electrochem. Commun. 2006, 8 , 1665.

[11] F. N. Crespilho, T. F. C. C. Borges, V. Zucolotto, F. C. Nart, O. N. Oliveira Jr., J. Nanosci. Nanotechnol. 2006, 6, 2588.

[12] F. N. Crespilho, V. Zucolotto, J. R. Siqueira Jr., C. J. L. Constantino, F. C. Nart, O. N. Oliveira Jr., Environ. Sci. Technol. 2005, 39, 5385.

[13] P. J. Kulesza, M. A. Malik, J. Skorek, K. Miecznikowski, S. Zamponi, M. Berrettoni, M. Giorgetti, R. Marassi, J. Electrochem. Soc. 1999, 146, 3757.

[14] A. A. Karyakin, E. E. Karyakina, Electrochem. Commun. 1999, 1,78

[15] M. Galkowski, M. A. Malik, P. J. Kulesza, H. Bala, K. Miecznikowski, R. Wlodarczyk, L. Adamczyk, M. Chojak, J. Electrochem. Soc. 2003, 150, 249.

[16] A. A. Karyakin, Electroanalysis 2001, 13, 813.
[17] R. Koncki, Crit. Rev. Anal. Chem. 2002, 32, 79.

[18] D. Ivekovic, S. Milardovic, B. S. Grabaric, Biosens. Bioelectron. 2004, 20, 872.

[19] S.-M. Chen, C.-M. Chan, J. Electroanal. Chem. 2003, 543, 161.

[20] M. Florescu, C. M. A. Brett, Anal. Lett. 2004, 37, 871.

[21] R. Pauliukaite, M. E. Ghica, C. M. A. Brett, Anal. Bioanal. Chem. 2005, 381, 972.

[22] D. R. Shankaran, S. S. Narayanan, Fresenius J. Anal. Chem. 1999, 364, 686.

[23] N. R. de Tacconi, K. Rajeshwar, R. O. Lezna, Chem. Mater. 2003, 15, 3046.

[24] S. de Luca, M. Florescu, M. E. Ghica, A. Lupu, G. Palleschi, C. M. A. Brett, D. Compagnone, Talanta 2005, 68, 171.

[25] S. Milardović, Z. Grabarić, B. S. Grabarić, Food Technol. Biotechnol. 2000, 38, 203.

[26] S. Zamponi, M. Berrettoni, P. J. Kulesza, K. Miecznikowski, M. A. Malik, O. Makowski, R. Marassi, Electrochim. Acta 2003, 48, 4261.

[27] M. H. Pournaghi-Azar, H. Razmi-Nerbin, J. Electroanal. Chem. 1998, 456, 83.

[28] N. R.de Tacconi, K. Rajeshwar, R. O. Lezna, J. Electroanal. Chem. 2006, 587, 42.

[29] F. N. Crespilho, V. Zucolotto, O. N. Oliveira Jr, F. C. Nart, Int. J. Electrochem. Sci. 2006, 1, 194. 